\title{
PAPER
}

\section{Outcome of epilepsy surgery in focal cortical dysplasia}

\section{T Kral, H Clusmann, I Blümcke, R Fimmers, B Ostertun, M Kurthen, J Schramm}

See end of article for authors' affiliations

.....................

Correspondence to: Dr T Kral, Department of Neurosurgery, University of Bonn Medical Centre, Sigmund Freud Strasse 25, 53105 Bonn, Germany; thomas.kral@ ukb.uni-bonn.de

Received

1 November 2001

In final revised form:

27 September 2002

Accepted

23 October 2002

\begin{abstract}
Objective: To describe the outcome of surgery in patients with drug resistant epilepsy and a histopathological diagnosis of focal cortical dysplasia.

Methods and subjects: Analysis of histories and presurgical and follow up data was carried out in 53 patients with a histological diagnosis of focal cortical dysplasia. Their mean age was 24.0 years (range 5 to 46 ), and they included 14 children and adolescents. Mean age at seizure onset was 12.4 years $(0.4$ to 36$)$ and mean seizure duration was 11.6 years ( 1 to 45$)$.

Results: The presurgical detection rate of focal cortical dysplasia with magnetic resonance imaging (MRI) was 96\%. There were 24 temporal and 29 extratemporal resections; additional multiple subpial transections were done in 12 cases to prevent spread of seizure discharges. There was a $6 \%$ rate of complications with permanent neurological deficit, but no deaths. All resected specimens were classified by neuropathological criteria as focal cortical dysplasia. Balloon cells were seen in most cases of extratemporal focal cortical dysplasia. After a mean follow up of 50 months, 38 patients $(72 \%)$ were seizure-free, two $(4 \%)$ had less than two seizures a year, nine $(17 \%)$ had a reduction of seizure frequency of more than $75 \%$, and four $(8 \%)$ had no improvement. Seizure outcome was similar after temporal and extratemporal surgery. The patients in need of multilobar surgery had the poorest outcome.

Conclusions: Circumscribed lesionectomy of focal dysplastic lesions provides seizure relief in patients with chronic drug resistant temporal and extratemporal epilepsy. There was a trend for the best seizure outcome to be in patients with early presurgical evaluation and early surgery, and in whom lesions were identified on the preoperative MRI studies.
\end{abstract}

D isrupted cerebral cortical cytoarchitecture, identified by neuropathological studies of surgical specimens or necropsy analysis in patients with drug resistant epilepsy, is a common structural lesion in epileptogenic foci, occurring in $20-30 \%$ of cases. The terms focal cortical dysplasia, microdysgenesis, dysgenetic malformations, neuronal migration disorders, dysmorphogenesis, and glioneuronal hamartomas/hamartias are often used synonymously to describe a malformational focal epileptogenic lesion associated with seizure activity. Although most studies use the term focal cortical dysplasia, there are discrepancies in the terminology of these lesions with respect to their extent and localisation, as well as their underlying pathogenesis. ${ }^{1-3}$

Little is known about the pathophysiological basis of the epileptiform activity, but the influence of the neuronal population and perilesional changes in the neurochemical profile are considered to be major epileptogenic pathomechanisms. ${ }^{4}$ Disorganised or absent lamination with neuronal heterotopia is either circumscribed or widespread. Localised disorganised masses of tissue composed of mature neuronal or glial cell elements are typical of focal cortical dysplasia. ${ }^{5-7}$ Dysplastic balloon cells of immature neural phenotype can often be identified in these lesions. ${ }^{8}$

Several reports have related the pathological findings of dysplastic lesions to the outcome of surgical treatment in patients with drug resistant epilepsy. The outcome has been rather unfavourable in most of these studies, but prognostic factors have rarely been identified. ${ }^{15}{ }^{10}$ Our aim in this study was to assess seizure relief following resection of lesions characterised as "dysplastic" in nature, and to verify the impact of preoperative magnetic resonance imaging (MRI), other clinical findings, and neuropathological findings with respect to postsurgical prognosis. This involved a retrospective review of 53 patients with drug resistant epilepsy.

\section{METHODS}

We examined the records of all juvenile and adult patients with chronic drug resistant epilepsy (of more than one year's duration) who were treated in the local epilepsy surgery programme during between January 1989 and December 1999. A histological diagnosis of focal cortical dysplastic lesions was confirmed in 64 of these. Patients who had hemipherectomy for dysplasia were excluded; these are described in another paper. ${ }^{11}$ Patients with a preoperative MRI carried out elsewhere that was either of poor quality or not available for review were also excluded, as were those without clinical follow up $(\mathrm{n}=11)$, leaving a study population of 53 patients.

Most data were collected prospectively, but all clinical records were re-evaluated for seizure history, presence of febrile seizures, seizure type, auras, non-invasive or invasive electrophysiological evaluation, surgical procedures, and follow up. Follow up data were collected at three monthly intervals in the first year and annually in the ensuing years. The surgical outcome was classified as: class I, seizure-free, auras only; class II, no more than two seizures a year; class III, reduction in seizure frequency by more than $75 \%$; class IV, reduction in seizure frequency by less than $75 \% .{ }^{12}$

\section{Presurgical evaluation}

All patients had presurgical MRI and, if necessary, computed tomography (CT). Presurgical MRI was done using a 1.5 Tesla system (Philips Medical Systems, Einthoven, Netherlands). The following sequences were obtained: sagittal Tl weighted spin echo (slice thickness $5 \mathrm{~mm}$, interslice gap $0.5 \mathrm{~mm}$ ); axial FLAIR and T2 weighted fast spin echo (slice thickness $5 \mathrm{~mm}$, interslice gap $0.5 \mathrm{~mm}$ ); coronal FLAIR (slice thickness 2 to 5 $\mathrm{mm}$, interslice gap 0.2 to $0.5 \mathrm{~mm}$ ); coronal Tl weighted inversion recovery (slice thickness $5 \mathrm{~mm}$, interslice gap $0.5 \mathrm{~mm}$ ); and axial $\mathrm{Tl}$ weighted spin echo (slice thickness $5 \mathrm{~mm}$, interslice gap $0.5 \mathrm{~mm}$ ), before and after GD-DTPA injection. CT 
Table 1 Demographic data

\begin{tabular}{llll}
\hline Variable & $\begin{array}{l}\text { Adolescent patients } \\
(<18 \text { years) }\end{array}$ & Adult patients & Total \\
\hline Number of patients & 14 & 39 & 53 \\
Female & 10 & 17 & 27 \\
Male & 4 & 22 & 26 \\
Age at surgery (years) & $11.6(5$ to 17$)$ & $28.4(18$ to 46$)$ & $24.0(5$ to 46$)$ \\
Age at seizure onset (years) & $6.0(0.8$ to 12) & $14.7(0.4$ to 36$)$ & $12.4(0.4$ to 36$)$ \\
Duration of seizures (years) & $5.7(1$ to 15) & $13.7(1$ to 45$)$ & $11.6(1$ to 45$)$ \\
\hline Values are $\mathrm{n}$ (range) & & &
\end{tabular}

scans were obtained with slice thickness of $4 \mathrm{~mm}$ infratentorially and $8 \mathrm{~mm}$ supratentorially (Somatom Plus, Siemens, Erlangen, Germany) The criteria for radiological diagnosis of focal cortical dysplasia are described elsewhere. ${ }^{13}$

Functional imaging with PET or SPECT, as well as intracarotid amobarbital testing of language and memory, were used as adjuncts when needed. ${ }^{14}$ All patients received comprehensive neuropsychological testing of attention, memory, language, and higher verbal and visual reasoning. ${ }^{15}$ The presurgical electrophysiological location was based on a surface electroencephalogram (EEG) and included placement of sphenoidal electrodes in all patients with temporal lobe epilepsy. Invasive recordings from chronically implanted electrodes were used in the following circumstances:

- inconclusive or discordant results from non-invasive procedures, especially from interictal and ictal EEG where recorded;

- non-lesional high resolution MRI or questionable lesions not clearly distinguishable from normal tissue (for example, cortical dysplasia);

- localisation of the assumed epileptogenic lesion close to or overlapping eloquent areas (motor cortex, language area, and so on), thus requiring electrical stimulation for cortical mapping.

Twelve of 24 patients with temporal lobe epilepsy and 20 patients with extratemporal lobe epilepsy underwent invasive EEG evaluation. Strip electrodes alone were implanted in 15 patients, and strip electrodes in combination with intrahippocampal depth electrodes in another three. Grid electrodes were used in 10 patients and a combination of grid and depth electrodes in one. A single grid electrode was used in three patients. Intraoperative electrocorticography was not used in this series.

The combination of clinical, non-invasive and invasive neurophysiological data, neuroimaging results, neuropsychological findings, and analysis of cognitive functions made it possible to define monolobar or multilobar resection zones in all patients.

\section{Surgical procedures}

Resective surgery-that is, lobectomy, lesionectomy or corticectomy, or multiple subpial transsections of the eloquent ictal area-was the major surgical approach. All operations were done under general anaesthesia, as mapping of language function was usually undertaken extraoperatively.

If a lesion was detectable on MRI, the aim of surgery was the complete removal of the lesion and the ictal zone. A lesionectomy was accompanied in the majority of cases by corticectomy of the surrounding cortex, extending to a minimum of at least $0.5 \mathrm{~cm}$ and a maximum of $1 \mathrm{~cm}$-that is, lesionectomy with a rim. If no lesion was detectable on MRI $(n=2)$, the extent of the corticectomy of the epileptogenic zone was guided by the results of earlier invasive EEG recordings. Because intraoperative electrocorticography was never used in this series to guide the surgeon, the results obtained from the presurgically implanted strips and grids obviously had to have been sufficiently clear. In the temporal lobe, the lateral resection line extended 4.5 to $5.5 \mathrm{~cm}$ from the superior to the inferior temporal gyrus in the non-dominant hemisphere, and $4.5 \mathrm{~cm}$ in the language dominant hemisphere. In
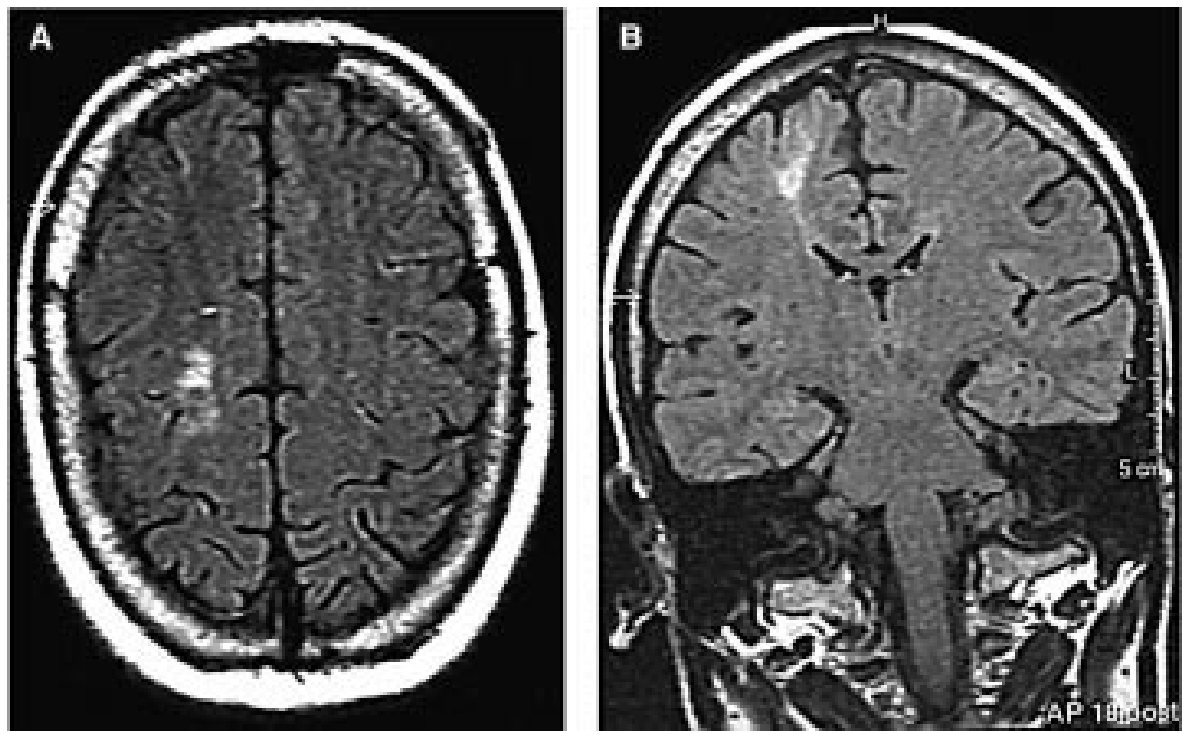

Figure 1 Magnetic resonance imaging of the brain of a patient with drug resistant epilepsy and ictal activity of the right frontodorsal cortex. A frontodorsally located area of focal cortical dysplasia, characterised as a hyperintensive focal lesion with disconfigured grey/white matter, is visible on the axial (A) and coronal (B) planes (flair weighted MRI scan). 
Table 2 Seizure outcome

\begin{tabular}{|c|c|c|c|c|c|}
\hline & \multirow[b]{3}{*}{$\mathrm{N}$} & \multicolumn{4}{|c|}{ Outcome class* } \\
\hline & & \multicolumn{2}{|l|}{ I/II } & \multicolumn{2}{|c|}{ III/IV } \\
\hline & & $\mathrm{n}$ & $\%$ & $\mathrm{n}$ & $\%$ \\
\hline \multicolumn{6}{|l|}{ (A) Age at surgery $\dagger$} \\
\hline Age $<18$ years & 14 & 13 & 94 & & \\
\hline Adult & 39 & 27 & 69 & 12 & 31 \\
\hline \multicolumn{6}{|l|}{ (B) Location of surgery } \\
\hline Temporal & 24 & 19 & 79 & 5 & 21 \\
\hline Extratemporal & 29 & 21 & 72 & 9 & 28 \\
\hline Total & 53 & 40 & 75 & 13 & 25 \\
\hline \multicolumn{6}{|l|}{ (C) Surgical strategy } \\
\hline Lobectomy & 20 & 13 & 65 & 7 & 35 \\
\hline Temporal lobectomy & 17 & 13 & 76 & 4 & 24 \\
\hline Extratemporal lobectomy & 3 & & & 3 & 100 \\
\hline Lesionectomy & 33 & 27 & 82 & 6 & 18 \\
\hline Multilobar lesionectomy & 1 & & & 1 & 100 \\
\hline Monolobar temporal lesionectomy & 7 & 6 & 86 & 1 & 14 \\
\hline Monolobar extratemporal lesionectomy & 25 & 21 & 84 & 4 & 16 \\
\hline Resective surgery without MST & 41 & 31 & 76 & 10 & 24 \\
\hline Resective surgery with MST & 12 & 9 & 75 & 3 & 25 \\
\hline Lobectomy with MST & 1 & 1 & 100 & & \\
\hline Lesionectomy with MST & 11 & 8 & 73 & 3 & 27 \\
\hline
\end{tabular}

patients who received temporolateral lesionectomy or corticectomy and where MRI and EEG monitoring indicated temporomesial involvement or seizure generation, the temporomesial structures-that is, the amygdala, uncus, and hippocampal and parahippocampal gyri-were also resected.

Patients with unilobar but multifocal epileptogenic activity were selected for lobectomy. Frontal lobectomy was combined with anterior two thirds or complete corpus callosotomy if bilateral ictal activity was detected. Additional monolobar or multilobar multiple subpial transsections were done, using Wyler's modification, ${ }^{16}$ to prevent the spread of seizure discharges in eloquent areas if ictal dischargers or interictal spikes were found in those areas during presurgical evaluation, or if the semiology suggested involvement of eloquent cortical areas adjacent to the lesion.

\section{Neuropathological examination}

Histological evaluation was possible in all 53 patients. The resected specimens were assessed using a standardised neuropathological examination protocol described in detail previously. ${ }^{17}$ Haematoxylin-eosin (H\&E), Nissl, and combined $\mathrm{H} \& \mathrm{E} / \mathrm{Luxol}$ fast blue stains, as well as immunohistochemical reactions for glial fibrillary acidic protein, synaptophysin, neurofilament protein, and Ki-67, were available. All specimens had been examined by two neuropathologists and were now reviewed by a third neuropathologist (IB) experienced in the field of epileptogenic lesions.

\section{Statistical analysis}

Data were analysed using commercially available statistical software; $\chi^{2}$ tests, the Fisher exact test, and the rank-sum test were used for univariate analysis. A probability $(p)$ value of $<0.05$ was deemed significant. If significant variables were found, a multivariate procedure was undertaken.

\section{RESULTS}

\section{Clinical data}

Fourteen children and adolescents were included in the study group of 53 patients. There was a wide range in both age at seizure onset and duration of seizures (table 1).
The following seizure types were identified: simple partial seizures (SPS; $\mathrm{n}=13$ ); complex partial seizures (CPS; $n=51)$; and generalisation of SPS or CPS $(n=18)$. Generalised myoclonic seizures $(n=1)$ and generalised tonic-clonic seizures with falling were observed in two children. Eleven of 15 patients with an aura in their history and all three patients with febrile seizures had a temporal seizure origin.

A structural lesion (fig 1) corresponding to EEG abnormalities was identified on preoperative MRI in $96 \%$ of cases $(\mathrm{n}=51)$ and a combination of neocortical temporal lesions and Ammon's horn sclerosis was found in two of 24 patients with temporal lobe epilepsy. No other structural abnormalities - such as tumours or vascular malformationswere detected in the study. Three patients with temporal seizure onset and one with extratemporal onset had no abnormalities on preoperative MRI analysis when reevaluated by a neuroradiologist.

A monolobar surgical approach was used in 24 patients with a temporal epileptogenic area and in 28 patients with an extratemporal epileptogenic area. Lobectomy $(n=20)$ or lesionectomy/corticectomy $(\mathrm{n}=33$ ) were standardised procedures. Temporal lobectomy and frontal lesionectomy were the most commonly used procedures (table $2 \mathrm{~B}$ ). A resection of the temporomesial structures was done in $83 \%$ of patients with temporal lobe epilepsy. Frontal lobectomy was combined with corpus callosotomy in one patient. The frontal and temporal lobes were resected in one other patient with atrophy and epileptogenic discharges in both these lobes. The majority of extratemporal resections involved the frontal lobe $(n=22)$ rather than the parietal $(n=4)$ or occipital lobes $(n=2)$. Additional monolobar $(n=8)$ or multilobar $(n=4)$ multiple subpial transsections were aimed at preventing the spread of seizure discharges into eloquent areas (table 2C). The type of surgical procedure was not related to age.

Infection of the bone flap $(\mathrm{n}=1)$ and meningitis $(\mathrm{n}=1)$ were the main postoperative surgical complications. Four patients had transient neurological deficits after multiple subpial transsections. Two patients developed permanent hemianopsia after temporal lobe surgery and one had a permanent hemiparesis after an ischaemic insult to the internal capsule. No deaths were seen in this group. 

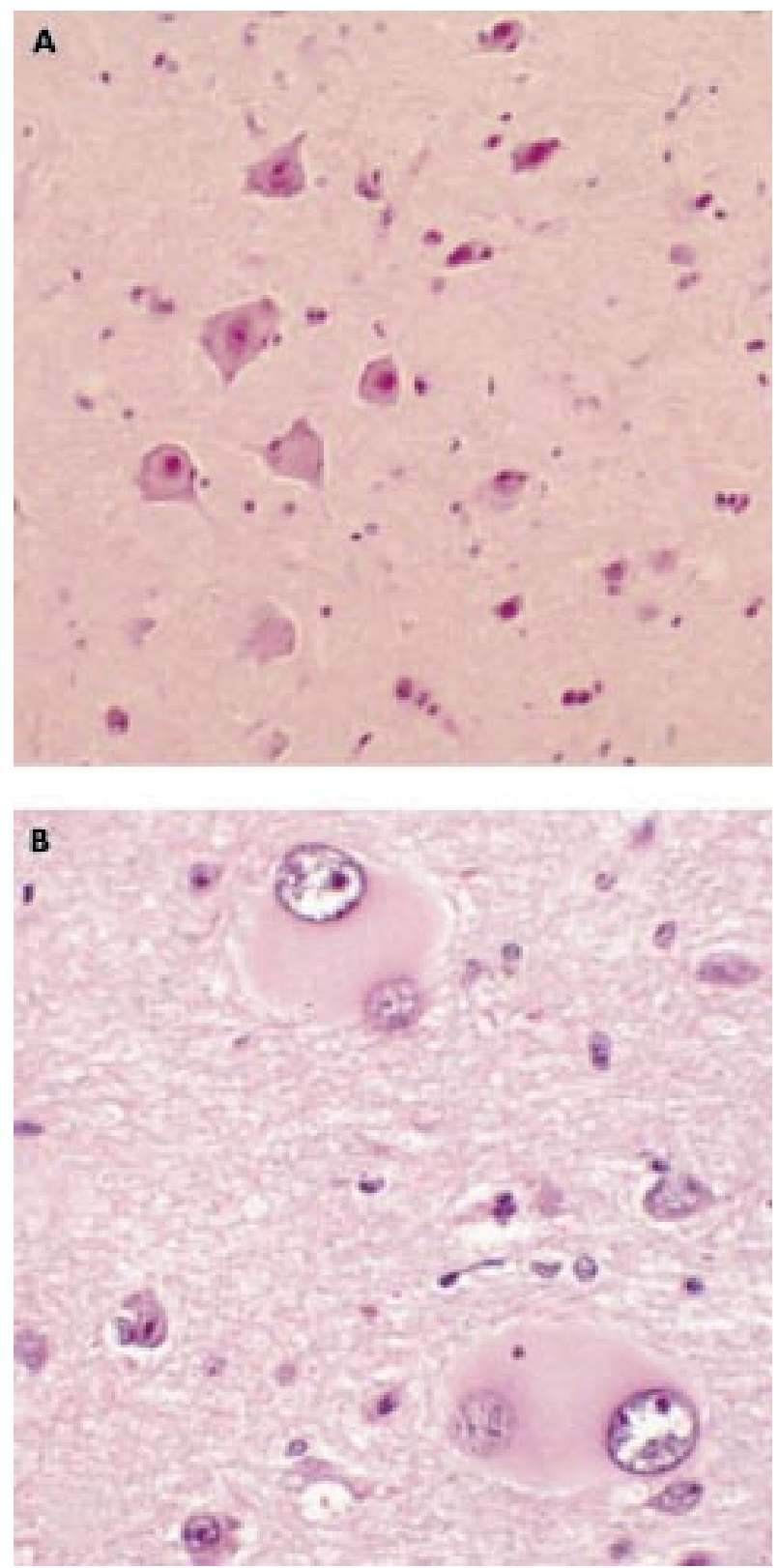

Figure 2 (A) Histological manifestation of focal cortical dysplasia. Note the dysplastic architecture of cortical neurones. (B) Typical histological feature of extratemporal focal cortical dysplasia with hypertrophic balloon cells (forme fruste of tuberous sclerosis).

\section{Neuropathology}

Surgical specimens were examined and classified by a neuropathologist for the presence of neoplastic or malformative lesions. All specimens with features of glial or glioneuroneal dysplastic lesions were included. Dysembryoplastic neuroepithelial tumours ${ }^{18}$ were excluded from this study. Focal cortical dysplasia was the most common specific pathology $(n=53)$. Of 28 cases of extratemporal focal cortical dysplasia, 21 showed additional bizarre and hypertrophic balloon cellsthat is, the forme fruste of tuberous sclerosis; only two of 24 cases of temporal focal cortical dysplasia showed these cells. The subgroup of patients with focal cortical dysplasia and balloon cells had no other clinical or radiological signs of tuberous sclerosis. ${ }^{19}$ The characteristic histological presentation of focal cortical dysplasia with and without balloon cells is shown in fig 2.

The coexistence of neurones in white matter, Ammon's horn sclerosis, and/or low grade glioma was found in six resected lesions. "Dual pathology," proposed by Levesque et al to describe the coincidence of extrahippocampal temporal lesions with Ammon's horn sclerosis, ${ }^{20}$ was observed in two patients (table 3).

\section{Seizure outcome}

After a mean follow up of 50 months (range 12 to 141), 38 patients $(72 \%)$ were seizure-free (class I), two (4\%) had no more than two seizures a year (class II), nine (17\%) had a reduction in seizure frequency of more than $75 \%$ (class III), and four ( $8 \%$ ) had no improvement (class IV). There was no correlation between a favourable outcome (class I and II) and the duration of follow up.

With the exception of age at surgery, other demographic data such as sex, age at seizure onset, aura, febrile seizures, and seizure types had no relevance to postoperative seizure relief.

Children and adolescents $(\mathrm{n}=14)$ appeared to have a better seizure outcome, though this was not significant in a $\chi^{2}$ test (table 2A).

The result of the preoperative MRI analysis was an important predictive factor. Of 51 patients with a structural lesion on MRI, $68 \%$ had a favourable outcome after lobectomy and $84 \%$ after lesionectomy (class I and II) (table 4). Lateralisation and localisation of epileptogenic activity was not correlated with seizure outcome. Multilobar surgical approaches and lobectomies were always less successful than monolobar approaches and circumscribed lesionectomies (table 2C). An excellent surgical outcome (class I and II) was observed following circumscribed extratemporal or temporal lesionectomies in $84 \%$ and $86 \%$ of the patients, respectively (table $2 \mathrm{C}$ ). An aggressive preoperative workup with a high percentage of invasive EEG evaluation and a high rate of lesion detection on the preoperative MRI was associated with more successful results in the group with monolobar lesionectomy than in those with monolobar lobectomy, and did not improve the poor outcome of the group with multilobar surgery (table 4). The outcome of 12 patients who had lobectomy/lesionectomy and multiple subpial transsections was comparable with that of the group with temporal lobectomies (table 2C).

Analysis of the histopathological subgroups revealed that patients with focal cortical dysplasia and balloon cells had the best seizure outcome (class I/II, 78\%) and the small group of patients with focal cortical dysplasia and Ammon's horn sclerosis or coexistence of focal cortical dysplasia with low grade glioma had the worst outcome (class I/II, 50\%; table 3).

\section{DISCUSSION}

Recent progress in MRI and EEG monitoring techniques has opened new avenues for the identification and epileptological characterisation of structural lesions underlying focal ictal activity. Dysplastic lesions of various sizes and locations are now more often detected in patients with drug resistant epilepsy. ${ }^{21}$ Although presurgical evaluation and surgical techniques have improved in recent years, the postoperative success rate still appears limited ${ }^{10}{ }^{10}$ when compared with epilepsy associated with low grade tumours or mesial temporal sclerosis. $^{22} 23$

So far, there have been no studies focusing on standardised inclusion criteria and analysing the predictive impact of clinical data, MRI findings, and different neuropathological features of patients with drug resistant epilepsy and dysplastic lesions. In this study, we have investigated the subgroup of surgically treated epilepsy patients with focal dysplastic lesions. This subgroup has been described in only a few other surgical series. The mean age at entry into the study (24.0 years) and the frequency of seizure manifestations in childhood were not significantly different from other reports. ${ }^{1524}$ Early seizure manifestations during childhood and surgery in adolescence point to a high epileptogenic 
Table 3 Pathological findings and seizure outcome

\begin{tabular}{|c|c|c|c|c|c|}
\hline \multirow[b]{3}{*}{ Pathological diagnosis } & \multirow[b]{3}{*}{$\mathrm{N}$} & \multicolumn{4}{|c|}{ Outcome class* } \\
\hline & & \multicolumn{2}{|l|}{$1 / I I$} & \multicolumn{2}{|c|}{ III/IV } \\
\hline & & $\mathrm{n}$ & $\%$ & $\mathrm{n}$ & $\%$ \\
\hline Focal cortical dysplasia & 53 & 40 & 75 & 13 & 25 \\
\hline Focal cortical dysplasia with tuberous sclerosis & 23 & 18 & 78 & 5 & 22 \\
\hline Focal cortical dysplasia without tuberous sclerosis $\dagger$ & 30 & 22 & 73 & 8 & 27 \\
\hline Focal cortical dysplasia and associated pathological diagnosis $†$ & 6 & 3 & 50 & 3 & 50 \\
\hline Low grade glioma & 3 & 1 & 33 & 2 & 67 \\
\hline Ammon's horn sclerosis & 2 & 1 & 50 & 2 & 67 \\
\hline Neurones in white matter & 1 & 1 & 100 & & \\
\hline
\end{tabular}

Table 4 Clinical data, surgical approach, and outcome

\begin{tabular}{|c|c|c|c|}
\hline Surgical approach & $\begin{array}{l}\text { Monolobar lobectomy } \\
\text { (n (\% class I/II)) }\end{array}$ & $\begin{array}{l}\text { Monolobar lesionectomy } \\
\text { (n (\% class I/III) }\end{array}$ & $\begin{array}{l}\text { Multilobar surgery } \\
\text { (n (\% class I/II)) }\end{array}$ \\
\hline $\begin{array}{l}\text { All patients with the } \\
\text { same surgical } \\
\text { approach }\end{array}$ & $20(65)$ & $32(84)$ & $1(0)$ \\
\hline \multicolumn{4}{|l|}{ Preoperative evaluation } \\
\hline MRI, lesion detected & $19(68)$ & $31(84)$ & $1(0)$ \\
\hline $\begin{array}{l}\text { Invasive EEG + MRI } \\
\text { lesion }\end{array}$ & $8(75)$ & $22(77)$ & $1(0)$ \\
\hline $\begin{array}{l}\text { Outcome class (I to IV) } \\
\text { Patients with monolobar } \\
\text { I/III. } \\
\text { EEG, electroencephalog }\end{array}$ & $\begin{array}{l}\text { based on the classificati } \\
\text { r lesionectomy and/or le } \\
\text { graphy; MRI, magnetic re }\end{array}$ & $\begin{array}{l}\text { f Engel. }{ }^{12} \\
\text { s on preoperative MRI had } \\
\text { ance imaging. }\end{array}$ & lent outcome $184 \%$ clas \\
\hline
\end{tabular}

capacity of these dysplastic lesions ${ }^{9}$ and may explain the relatively good outcome of surgery in this series.

Most dysplastic lesions were located in the temporal lobe, which supports the findings of Rojiani et al of increased neuronal heterotopia in the temporal white matter of normal individuals, and his hypothesis of a possible relation to the higher frequency of malformational lesions in the temporal lobe. ${ }^{25}$

In this study excellent seizure relief (class I) was obtained in $72 \%$ of the patients, and in $93 \%$ of children and adolescents. This supports the view that early evaluation and surgical treatment is beneficial in cases of drug resistant epilepsy. ${ }^{26}{ }^{27}$ Resective surgery in other series with dysplastic or malformational lesions was less successful. In a series of 52 patients with dysplastic lesions, $52 \%$ were seizure-free, ${ }^{24}$ while in another series of 17 patients, $35 \%$ were seizure-free; in a series of patients with microdysgenic features, 39\% were seizure-free ${ }^{28}$; and of 26 patients with focal neuronal migration disorders, $42 \%$ were seizure-free. ${ }^{29}$

The development of more sensitive MRI methods ${ }^{13}$ together with increased experience has resulted in a high neuroradiological detection rate of dysplastic lesions ( $94 \%$ in the present study). In earlier reports on dysplastic and malformational lesions, detection rates have been between 32\% and 64\%. ${ }^{24} 2729$ The prognostic significance of structural alterations on MRI scans in the ictal area is supported by the favourable outcome in $84 \%$ of our group and was described as predictive by Armon et al. ${ }^{30}$ If the circumscribed lesion was associated with multifocal lobar ictal activity, as in the lobectomy group, the outcome was less satisfactory $(68 \%)$. Thus the most effective surgical approach in this series was a monolobar circumscribed lesionectomy, with success rates comparable to the surgical treatment of mesial temporal lobe epilepsy. ${ }^{23}$ In contrast to other reports, ${ }^{27}$ the outcomes following extratemporal and temporal lesionectomy did not differ (table 2C).

Detection of lesions on MRI and invasive EEG was less predictive in patients requiring lobectomy or multilobar surgery than circumscribed lesionectomy (table 4). It has been suggested that silent areas of cortical dysplasia which have not been resected resume ictal activity after a postsurgical interval. ${ }^{9}$ It should be emphasised that further improvements in evaluation may help to identify those patients who will not benefit from surgical treatment.

If the ictal activity involves an eloquent cortical area, multiple subpial transsections can help to isolate the epileptic focus from the adjacent cortex. ${ }^{1631}$ Cortical function was preserved in all cases in our study. However, the postsurgical seizure outcome in these cases was no different from the outcome in patients without multiple subpial transsections (table 2C), and was not as good as in other series. ${ }^{32}{ }^{33}$ Whether these patients will develop an increase in seizure frequency several years after surgery, as described by Orbach et $a l^{34}$ will be assessed in further studies.

Focal cortical dysplasia accompanied by Ammon's horn sclerosis or low grade gliomas that were not detected on preoperative MRI were associated with a somewhat worse seizure outcome, though the difference was not statistically significant. Temporomesial coexistence of focal cortical dysplasia and Ammon's horn sclerosis was rare in our study but may reflect a specific pathogenic pathway of mesial temporal lobe malformation..$^{35}$ The coexistence of focal cortical dysplasia and low grade tumours has been examined in a few clinical and pathological studies and the relation between glioneuroneal dysplasia and neoplasms has been discussed. ${ }^{36}$ However, in our study this group was excluded by definition.

Whether or not balloon cells were present in association with focal cortical dysplasia could not be determined on preoperative MRI in our series, but it may be possible to detect these by their characteristic appearance on high resolution MRI in future studies. ${ }^{13}$ Barkovich et al have classified focal cortical dysplasia without balloon cells as malformations resulting from abnormal cortical organisation, and focal cortical dysplasia with balloon cells as malformations reflecting a 
proliferation of abnormal cell types. ${ }^{3}$ Further development of genetic, neuropathological, and neuroimaging techniques may help to clarify the pathogenesis of the different dysplastic lesions, identify their preferential location, and develop a classification useful to the clinician. However, in the present study the focal cortical dysplasia variant with balloon cells was predominantly observed in the extratemporal location $(91 \%)$ and contrasts with the higher frequency of other dysplastic lesions in the temporal lobe-for example, ectopic neurones in the white matter. ${ }^{37}$ The histological detection of balloon cells in this study was not associated with a difference in outcome.

\section{Conclusions}

Circumscribed lesionectomy of focal dysplastic lesions results in seizure relief in many patients with chronic drug resistant temporal and extratemporal epilepsy. Early presurgical evaluation, identification of lesions on the preoperative MRI studies, and early surgery were associated with the best prognosis for long term seizure relief.

\section{ACKNOWLEDGEMENTS}

Supported by an SFB grant to JS and CE, a DFG grant to JS, and a BONFOR grant to TK. We thank E Behrens MD for help in establishing the database; B Eimann for help in completing patient data collection; the other surgeons involved in the programme for allowing us to use their cases ( $\mathrm{J}$ Zentner MD, D v Roost MD, E Behrens MD); and A Hufnagel MD and T Grunwald MD, who contributed substantially to the presurgical evaluation programme.

\section{Authors' affiliations}

T Kral, H Clusmann, J Schramm, Department of Neurosurgery, University of Bonn Medical Centre, Bonn, Germany

I Blümcke, Department of Neuropathology, University of Bonn Medical Centre

R Fimmers, Department of Statistics and Biometrics, University of Bonn Medical Centre

B Ostertun, Department of Neuroradiology, University of Bonn Medical Centre

M Kurthen, Department of Epileptology, University of Bonn Medica

Centre

Competing interests: none declared

\section{REFERENCES}

1 Hirabayashi S, Binnie CD, Janota I, et al. Surgical treatment of epilepsy due to cortical dysplasia: clinical and EEG findings. J Neurol Neurosurg Psychiatry 1993:56:765-70.

2 Leventer RJ, Phelan EM, Coleman LT, et al. Clinical and imaging features of cortical malformations in childhood. Neurology 1999;53:715-22.

3 Barkovich AJ, Kuzniecky RI, Jackson GD, et al. Classification system for malformations of cortical development: update 2001. Neurology 2001;57:2168-78.

4 Chevassus-au-Louis N, Baraban SC, Gaiarsa JL, et al. Cortical malformations and epilepsy: new insights from animal models. Epilepsia 1999:40:811-21.

5 Taylor DC, Falconer MA, Bruton CJ, et al. Focal dysplasia of the cerebral cortex in epilepsy. J Neurol Neurosurg Psychiatry 1971;34:369-87.

6 Sisodiya SM, Free SL, Stevens JM, et al. Widespread cerebral structural changes in patients with cortical dysgenesis and epilepsy. Brain $1995 \cdot 118: 1039-50$

7 Crino PB, Eberwine J. Cellular and molecular basis of cerebral dysgenesis. J Neurosci Res 1997;50:907-16

8 Cotter D, Honavar M, Lovestone S, et al. Disturbance of Notch-1 and Wnt signalling proteins in neuroglial balloon cells and abnormal large neurons in focal cortical dysplasia in human cortex. Acta Neuropathol (Berl) 1999;98:465-72.
9 Palmini A Gambardella A, Andermann F, et al. Intrinsic epileptogenicity of human dysplastic cortex as suggested by corticography and surgical results. Ann Neurol 1995;37:476-87.

10 Sisodiya SM. Surgery for malformations of cortical development causing epilepsy. Brain 2000;123:1075-91.

11 Schramm J, Kral T, Clusmann H. Transsylvian keyhole functional hemispherectomy. Neurosurgery 2001;49:891-900; discussion 900-1.

12 Engel J, Rasmussen TB. Outcome with respect to seizures. In: Engel J, ed. Surgical treatment of the epilepsies. New York: Raven Press, 1993:609-21.

13 Urbach H, Scheffler B, Heinrichsmeier T, et al. Focal cortical dysplasia of Taylor's balloon cell type: a clinicopathological entity with characteristic neuroimaging and histopathological features, and favorable postsurgical outcome. Epilepsia 2002;43:33-40

14 Kurthen M, Helmstaedter C, Linke DB, et al. Quantitative and qualitative evaluation of patterns of cerebral language dominance. An amobarbital study. Brain Lang 1994;46:536-64.

15 Helmstaedter C, Elger CE. Functional plasticity after left anterior temporal lobectomy: reconstitution and compensation of verbal memory functions. Epilepsia 1998;39:399-406

16 Wyler AR, Wilkus RJ, Rostad SW, et al. Multiple subpial transections for partial seizures in sensorimotor cortex. Neurosurgery 1995;37:1 122-7; discussion 1127-8.

17 Wolf HK, Wiestler OD. Surgical pathology of chronic epileptic seizure disorders. Brain Pathol 1993;3:371-80.

18 Kleihues P, Scheithaver BW. Histological typing of tumors of the central nervous system. Berlin: Springer Verlag, 1993.

19 Roach ES, Smith M, Huttenlocher P, et al. Diagnostic criteria: tuberous sclerosis complex. Report of the Diagnostic Criteria Committee of the National Tuberous Sclerosis Association. J Child Neurol 1992;7:221-4.

20 Levesque MF, Nakasato N, Vinters HV, et al. Surgical treatment of limbic epilepsy associated with extrahippocampal lesions: the problem of dual pathology. J Neurosurg 1991;75:364-70.

21 Raymond AA, Fish DR, Sisodiya SM, et al. Abnormalities of gyration, heterotopias, tuberous sclerosis, focal cortical dysplasia, microdysgenesis, dysembryoplastic neuroepithelial tumour and dysgenesis of the archicortex in epilepsy. Clinical, EEG and neuroimaging features in 100 adult patients. Brain 1995:118:629-60.

22 Zentner J, Hufnagel A, Wolf HK, et al. Surgical treatment of neoplasms associated with medically intractable epilepsy. Neurosurgery 1997;41:378-86; discussion 386-7.

23 Jeong SW, Lee SK, Kim KK, et al. Prognostic factors in anterior temporal lobe resections for mesial temporal lobe epilepsy: multivariate analysis. Epilepsia 1999;40:1735-9

24 Prayson RA, Estes ML. Cortical dysplasia: a histopathologic study of 52 cases of partial lobectomy in patients with epilepsy. Hum Patho 1995;26:493-500.

25 Rojiani AM, Emery JA, Anderson K, et al. Distribution of heterotopic neurons in normal hemispheric white matter: a morphometric analysis. $J$ Neuropathol Exp Neurol 1996;55:178-83.

26 Kral T, Kuczaty S, Blumcke I, et al. Postsurgical outcome of children and adolescents with medically refractory frontal lobe epilepsies. Childs Nerv Syst 2001:17:595-601.

27 Wyllie E, Comair YG, Kotagal P, et al. Seizure outcome after epilepsy surgery in children and adolescents. Ann Neurol 1998;44:740-8.

28 Eriksson S, Malmgren K, Rydenhag B, et al. Surgical treatment of epilepsy - clinical, radiological and histopathological findings in 139 children and adults. Acta Neurol Scand 1999;99:8-15.

29 Palmini A, Andermann F, Olivier A, et al. Focal neuronal migration disorders and intractable partial epilepsy: a study of 30 patients. Ann Neurol 1991;30:741-9.

30 Armon C, Radtke RA, Friedman AH, et al. Predictors of outcome of epilepsy surgery: multivariate analysis with validation. Epilepsia 1996:37:814-21.

31 Morrell F, Whisler WW, Bleck TP. Multiple subpial transection: a new approach to the surgical treatment of focal epilepsy. J Neurosurg 1989;70:231-9

32 Sawhney IM, Robertson IJ, Polkey CE, et al. Multiple subpial transection: a review of 21 cases. J Neurol Neurosurg Psychiatry 1995;58:344-9.

33 Smith MC. Multiple subpial transection in patients with extratemporal epilepsy. Epilepsia 1998;39(suppl 4):S81-9.

34 Orbach D, Romanelli P, Devinsky O, et al. Late seizure recurrence after multiple subpial transections. Epilepsia 2001;42:1316-19.

35 Raymond AA, Fish DR, Stevens JM, et al. Association of hippocampal sclerosis with cortical dysgenesis in patients with epilepsy. Neurology 1994:44:1841-5.

36 Becker LE. Central neuronal tumors in childhood: relationship to dysplasia. J Neurooncol 1995;24:13-19.

37 Kasper BS, Stefan H, Buchfelder $M$, et al. Temporal lobe microdysgenesis in epilepsy versus control brains. J Neuropathol Exp Neurol 1999;58:22-8. 